\section{A note on the evaluation of a}

\section{"computer date"}

\author{
ABRAHAM TESSER, University of Georgia, Athens, Ga. 30601
}

and

MICHAEL BRODIE, Kaiser-Permanente Hospital, Walnut Creek, Calif. 94596

Four hundred and nine students who attended a "computer dance" returned a questionnaire on which they had made a number of ratings of their dates. Significant correlations with attraction were obtained for physical attractiveness $(r=.69)$, "personality" $(r=.68)$, "character" $(r=.49)$, intelligence $(r=.39)$, and two indices of similarity $(x=.46, .56)$.

Two recent studies (Byrne, Ervin, \& Lamberth, 1970; Walster, Aronson, Abrahams, \& Rottman, 1966) have focused on the determinants of the liking for a computer date. Both have found that physical attractiveness is an important determinant. Byrne et al (1970) found that attitude similarity was also related to attraction. Walster et al (1966) found that intelligence had only negligible effects. The present study may be viewed as a partial replication and extension of these findings.

\section{METHOD}

Nine hundred and eighty-six questionnaires were distributed at a "computer dance" held at Purdue University. Each $\mathbf{S}$ was instructed to fill the questionnaire out in their own residences after the dance and then to return it via campus mail in the envelope provided. The following results are based on the responses of the 197 males and 212 females who returned usable questionnaries before the data analyses were undertaken.

Ss were asked to rank the importance of "personality," "looks," "intelligence," and "character" as attributes of a date. They were also asked to rate their dates with respect to "personality," "physical attractiveness," "intelligence," and "character." Ss were given a list of 25 specific activities and things (e.g., participant sports, movies) and were asked to indicate those which they liked (or disliked) in common, did not like in common, or did not find out about. Also, they were given a list of eight broad interest and attitude areas (e.g., intellectual interests, religious attitudes) and again responded to each by indicating similarity, dissimilarity, or no knowledge. Finally, an overall evaluation of the date was obtained by having Ss rate (1) how much they would like to go out with their dates again (5-point scale labeled at each point) and (2) how the date compared with other dates they had had (7-point graphic scale anchored with "Best Date"|"Worst Date").

\section{RESULTS}

The Ss indicated that the most important attribute of a date was the date's "personality" (mean rank = 1.46), followed by the date's "character" (mean rank $=2.59$; difference between personality and character, $t=15.03 ; \quad \mathrm{df}=408$; "looks" (mean rank $=2.69$; difference between "character" and "looks," $t=1.16$, n.s.). The least important attribute was date's "intelligence" (mean rank $=3.01$; difference between "looks" and intelligence," $t=3.92$; df $=408 ; p<.01$ ).

One might predict that the rating of the data on each of these attributes should correlate with the overall evaluation of the date with magnitudes that are a direct reflection of the importance rankings. That is, the more important the attribute, the higher should be its correlation with evaluation of the date. This prediction was not realized in that rated physical attractiveness ("looks") had an inordinately high correlation with overall evaluation. ${ }^{1}$ The correlations in order of magnitude were: Physical attractiveness $(r=.69)$, followed by "personality" $(\mathrm{r}=.68$; difference between correlations with physical attractiveness and "personality," $t=.33$, n.s.), followed by "character" $(\mathrm{r}=.49 ;$ difference between correlations with "personality" and "character," $t=5.46 ; \quad p<.001)$, followed by "intelligence" $(r=.39$; difference between correlation with "character" and "intelligence," $\mathrm{t}=2.23 ; \mathrm{p}<.05)$.

There are several possible interpretations of this lack of correspondence between ranked inportance of an attribute and its correlation with attraction. (1) Ss may be unwilling to admit or are $\mathrm{p}<.001$ ), followed by the date's
(2) unaware of the influence of physical attractiveness on their overall evaluation. (3) It takes longer to learn about "personality" and "character" than "looks." Thus, if the S had more time to learn about the other, "personality" and "character" might correlate higher with attraction. It is also interesting that this college sample said that "intelligence" was least important and, in fact, "intelligence" had the lowest correlation with overall evaluation.

The number of specific activities and things that the $S$ indicated he liked or disliked in common with his date and the number of broad interest and attitude areas in which the $S$ indicated he was similar to the date was tallied. The resulting correlation with attraction was .46 for specific activities and things and .56 for broad interest and attitude areas $(p<.001$ for both).

These data seem to replicate the Walster et al (1966) and Byrne et al (1970) results with respect to physical attractiveness and the Byrne et al results with respect to similarity. On the other hand, while the correlation with perceived intelligence is not as high as the others, it is still significant, unlike the nonsignificant results of Walster et al (1966). It should be borne in mind, in interpreting these results, however, that the major findings of the Byrne and Walster studies were based on independent (of the particular S) assessments of each of the attributes that were related to attraction. The present findings are based on each S's reported perception of his date's attributes. Thus, the ratings may be partially based on nonveridical perception or inaccurate/careless reporting. Finally, the relationships may be partially based on the influence of overall evaluation on the ratings of each attribute rather than vice versa.

\section{REFERENCES}

BYRNE, D., ERVIN, E, R., \& LAMBERTH, $J$. The continuity between the experimental study of attraction and real life computer dating. Journal of Personality \& Social Psychology, 1970, $16,157-165$.

WALSTER, E., ARONSON, V., ABRAHAMS, D., \& ROTTMAN, L. Importance of physical attractiveness in dating behavior. Journal of Personality \& Social Psychology, 1966, 4, 508-516. NOTE

1. For economy of space each of the correlations with overall evaluation reported is based on the average of both indices (i.e. desire to date again and comparisons with other dates). The indices are correlated .83 and the results with each looked at individually are almost identical. 